(D)

CORPUS PUBLISHERS

\section{Environmental}

Sciences and

\section{Ecology: Current Research (ESECR)}

\section{Volume 3 Issue 2, 2022}

\section{Article Information}

Received date : January 26, 2022

Published date: February 11, 2022

\section{${ }^{*}$ Corresponding author}

Ponyaev LP, Moscow Aviation Institute,

4, Volokolamskoe, shosse, Moscow, 125993, Russia

\section{Keywords}

Ecology; Mobility; Recharge; Plug; Unstop; Drive; City

\section{Abbreviations}

DLR: Develop the Robo Mobile; EV: Electric Vehicles; SMC: Superconductor Magnetic Connector; RID: Rechargein-Drive; IUS: Induction Underground System; SES: Stationary Electric Stations; IEA: Northern Region; HEM: Hybrid Electric Motion; HEP: Hybrid Electric Propulsion; FFS: Full Flight Simulation; EPBD: European Buildings Directive

Distributed under Creative Commons CC-BY 4.0

\title{
High Ecology New Creative PLUG MOBILITY Smart City Concept for mass EV Recharge-in-Drive (RID) Development
}

\section{LP Ponyaev", Kuprikov M Yu ${ }^{1}$, NM Kuprikov ${ }^{1}$, LL Ponyaeva ${ }^{1}$ and PH Vangeel ${ }^{2}$} ${ }^{1}$ Moscow Aviation Institute, Volokolamskoe, Russia ${ }^{2}$ AVERE Association, Square De Meeus 37, 1000 Brussels, Belgium

\section{Abstract}

The PLUG MOBILITY as the new high Ecology creative RID Project is an Innovative MAI Partnership of the new "Plug Mobility" Concept for Develop the Robo Mobile (DLR) project and future cooperation with EC to progress of know-how Ecological El-Grid Road Infrastructure for Electric Vehicles (EV) with Superconductor Magnetic Connector (SMC) for Dynamic Recharging: Any Free Time part side Ro Arm Contact and Safe Non Hand Movement as the "EV Plug-Socket Mobility" of the all Low Cost EV-City Taxi \& Sharing Service Non Limit Drive for Minimize Risks of COVID contacts, Energy Source of Battery Consumption/Price and Non Lost any Self Time \& Money to Recharge Stations as the main negative aspects of EV-Mobility. Innovation Proposal of the New Know How Simple Dynamic Robo Recharging-in-Drive System for Energy Share Economy of Smart Cities with Electro Energy Efficiency for E-Drivers Logo: "Non-Stop as You Need for all EV-Drive Any Time and Any Where".

Introduction

Over the past few years; the development of hybrid and electric mobile vehicles has achieved the greatest breakthrough successes in the development of mass highly ecological transport on the roads of many countries. Sales in a number of European countries in Norway; Germany; France; Switzerland; Italy in the whole direction of urban cars have overtaken traditional cars with an internal combustion engine. The tendency to protect the environment and preserve natural temperature conditions with a reduction in harmful carbon emissions reflects the accelerated development of the automotive industry with a focus on quiet and "clean" electric transport; while simultaneously developing convenient services and the infrastructure of charging stations or replacement centers for charged batteries that is needed everywhere. And if it were not for the problems with high-performance charging; but limited expensive additional seats; then there could be even more new adherents of electric mobility. It is in this resolution of an acute problem in European historically developed cities and on highways that are not strongly tied to automakers that it makes sense to consider more efficient alternative and driverfriendly systems for recharging electric vehicles while driving without wasting time waiting for even high-speed recharging of batteries; in contrast to the traditionally simple and faster "filling" with gasoline or diesel fuel tank cars.

Projects and Opportunities for Fast Recharging of Electric Vehicles Directly While Driving Around the City or Highway

Any new road transport projects are always aimed at solving the most acute problems in large cities; on highways or near cities; and the promising result that can be seen in a few years will be visually presented. as can be seen in (Figure 1).

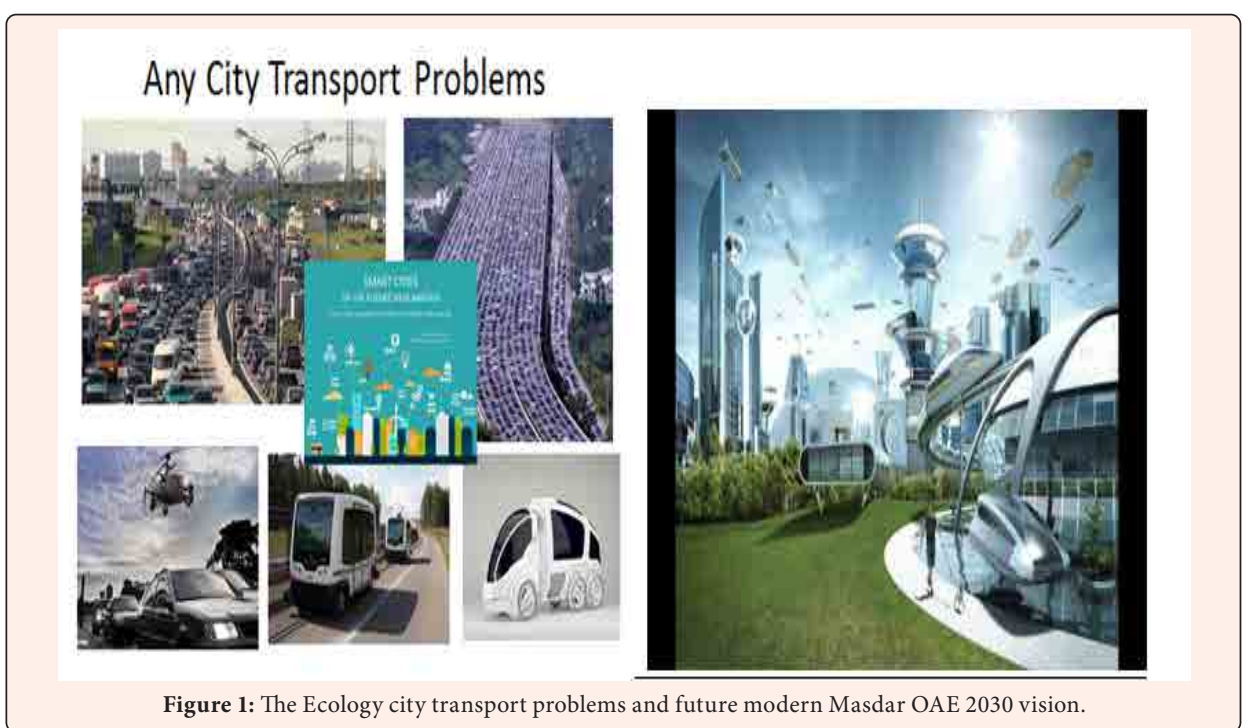

The main advantages of the new PLUG MOBILITY (PM) Concept of new optimal Recharge-in-Drive (RID) for Smart Urban City as complex analysis of the Cornell University (USA); British Energy Company (UK); Sweden; Israel and Italy focus to the ARENA del FUTURO Induction Underground System (IUS) that better strategy to recharge to the Full Recharge

How to cite this article : Ponyaev LP, Yu KM, Kuprikov NM, Ponyaeva LL, Vangeel PH (2022) High Ecology New Creative PLUG MOBILITY Smart City Concept for mass EV Recharge-in-Drive (RID) Development. Environ Sci Ecol: Curr Res 3: 1049 
Battery on the EV Stations in Chana and main aspects of progress efficiency vision goals to global best maximum results to EV-Mobility Service via development the new PLUG MOBILITY RID MAI project [1]

a) Electricity Efficiency is supplied directly to the EV-Mobility and Mini Battery charging in parallel any RID EV-Mobility in the Urban Cities

b) Not need 'hand connects' press COVID Risks and Non-Direct dependence on the Supply/Capacity of the Lithium-Ion Batteries mileage

c) Money Economy as don't overpay for the excess capacity of Expensive Big Batteries in the high Market Price of new E-cars

d) Use the Mini Battery as lighter and weight reduction of E-Cars allows to reduce specific Consumption and Energy resource

e) The decrease of the Batteries capacity allows to increase the number of service E-Taxi for the same amount of harmful extraction of Lithium

f) Green Technology as more Productions of Mini Batteries becomes less EnergyConsuming and harmful to the Ecology of the Earth

g) Easier to implement RID system of uniform distribution of Energy consumption and resources with cheaper Recharge Home Systems

h) Enhanced functionality for trouble-free Unmanned Auto City Pilot systems and Robo Mobile with AI as Point-on Line RID Know How

i) There is no need to limit the time of round-the-clock movement of an EV-Taxi or Car Sharing for the desired duration of Trips (Days \& Nights)

j) 10.It is not necessary to stop and there is no empty loss of time waiting for the Recharging EV-Mobility on the Stationary Electric Stations (SES)

k) 11.No need to leave the car and manually "by HAND" insert (as old view tech to Fuel Tank connect) the "Socket to Plug" to Recharge the EV

1) 12.High Economy self-money and significant savings in Personal Time for excessive storage of non-more new build E-energy stations in old City

m) 13.EV-Mobility priority becomes cheaper both when buying and when operating service with additional Sharing Economy Business Style

n) 14.It is easier to carry out the Transformation of Gasoline and Diesel Cars in a Hybrid Electric Mobile for Smart Ecology Green Cities

o) 15.It is easier to provide an increase in the duration and simple contacts by HT Superconductors Magnetic Connector (SMC) for RID points.

The Main Statistic Data and Barriers to New Rid Green Technology Worldwide Development

The significant barrier to the development of Electric Mobility is the lack of charging infrastructure in drive as more perspective then now. The presence of the AC charging station is a low power-required at a ratio of about 1.1 of the chargers to the electric car in most parts of the world. This assumption is confirmed in the Northern region (IEA) and in the United States (NREL). As the Statista Infographic shows; the number of charging stations in Germany is not keeping up with the growing number of electric vehicles. The number of charging stations on the machine amounted to 0.22 $0 ; 26$. At the end of 2021; it was at the level of 0.28-0;31 chargers per car [2] (Figure 2).

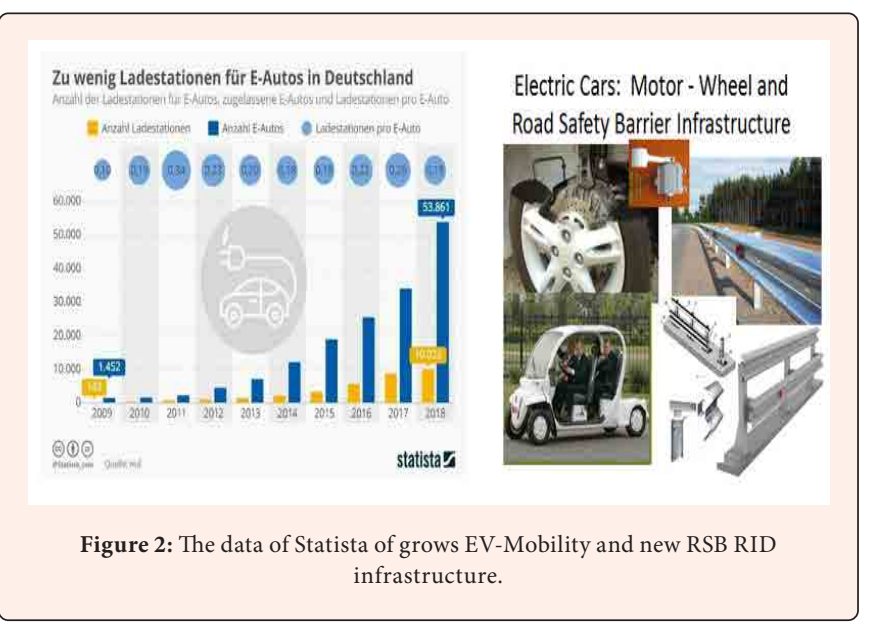

This PM RID project in MAI; Russia may be simple realize Innovation Technology of Zero-Toxic and Zero-Noise to Green Ecology Smart Cities Tomorrow any fast time together with Germany Partners as development DLR Robo Mobile or new Strategy of the Share Now. This know how Project will be high Efficiency Concept for All EV Drivers; Tourists and Business Guests with EV-Mobility Zero-P Style Life old and new Smart Ecology Green Cities for High Comfort; COVID Safety and Ecology EVTransportation Infrastructure Systems without Lost Time and Money [3] (Figure 3).

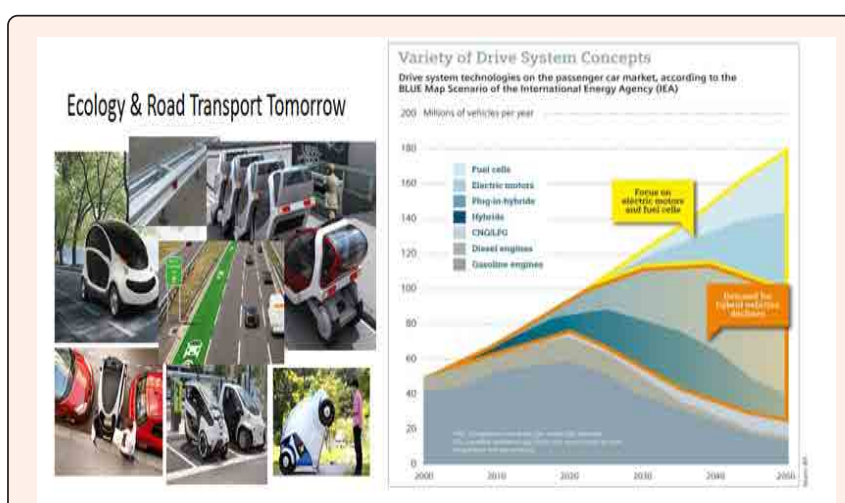

Figure 3: The Compact City EV-Mobility tomorrow and variety of Drive System Concepts.

\section{The Main Efficiency of the New PM Rid Concept Projection}

What energy savings are expected?-This Know-How Energy Optimization Project may be used to new Government Strategy Business Development of Green Ecology Urban Cities based on Economy and Electrical Energy Efficiency up to 35$50 \%$ by the Smart Electro Greed Infrastructure and Smart Road Charge-in-Drive Concept System for the Real-Time source of the EV-Mobility All Hybrid + Last Mile Concept; Transform Hybrid and E-Cars basing on the Non Limit Comfort Drive "PM RID Anytime to All" or by Unmanned Pilot EV-Taxi and Car Sharing Low Cost City Service Tomorrow and Future [4]. Thus; it is necessary to accelerate the development of the charging infrastructure and cover a large area with minimal costs for the modernization of the existing power network. Innovative proposal for this project from Russia for joint implementation-patenting of new Resource; Energy and TimeSaving Technologies in partnership with Germany DLR by know-how method and device for the implementation of a contact-roller or non-contact-induction method of dynamic charging-supply and better directly to motor of electric vehicles when they move in contactor with automatic spatial positioning to the safety barriers. We have private national patent with priority of the authors last year. Therefore; we ask the experts and organizers of the competition not to publicly these materials (Figure 4).

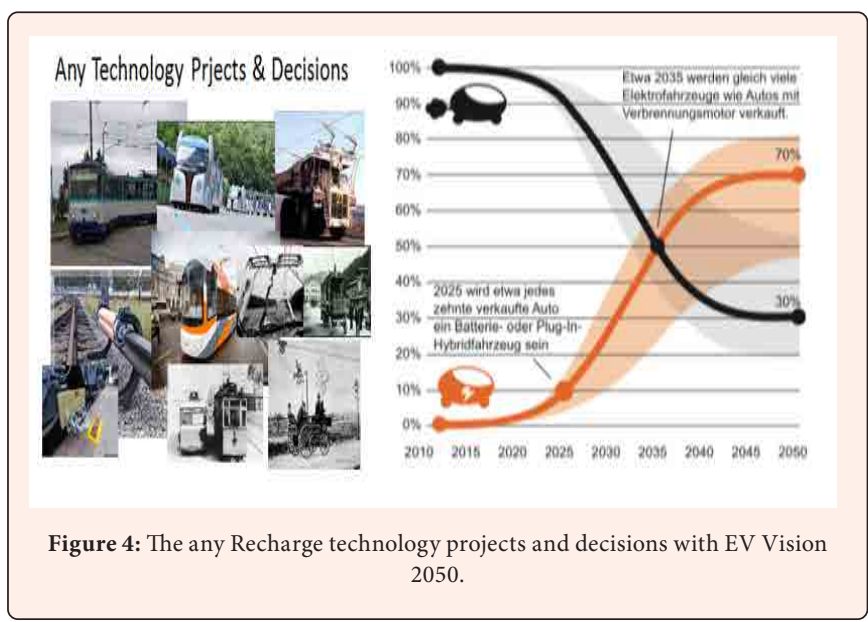

This Project may be priority fast Impulse to partnership with EC as this new Know How Innovation Idea for nearest future Engineering Modernizing the E-Car 
New Personality Digital Worldwide Concept Order Design with demo Additive 3D Technology Industry for Future Aerodynamic Shaped as the real Minimum Drag for Maximum Energy Efficiency of any City Mini E-Cars for Share Now Style. We had good skill for International R\&D Cooperation with Stuttgart University; EASN Academy and AVERE Association Strategy for the EC Expertise and Cooperation of the Hybrid Electric Propulsion (HEP) Aircraft R\&D 2020-2023. Also; we have skill to Design and Manufacture the Hybrid Electric Motion (HEM) platform of the Full Flight Simulation (FFS) with Certification in EASA by French THALES T\&S and L-3 Link in Crawley (UK); SJI(Italy) [5;6] (Figure 5).
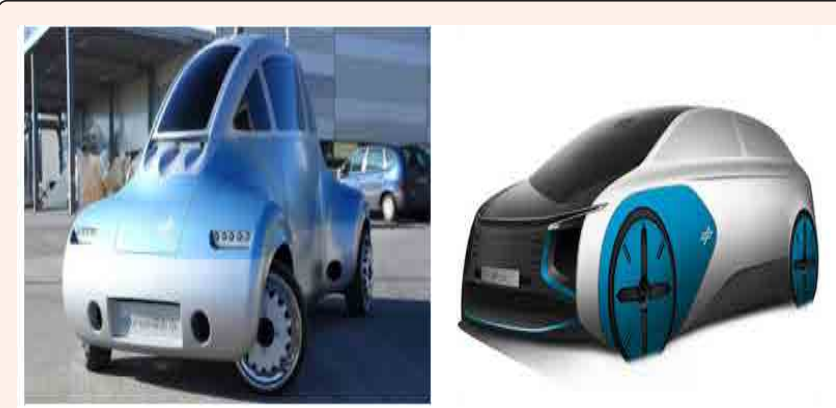

Figure 5: The DLR Robo Mobile and Italian EV-Mobility 2030 Eco Design future.

The Main Partners of PM Rid Project and Strategy Vision of the Avere EC Association

According to the European modern IMOTHEP and FUTPRINT50 Consortium project of Hybrid Electrical Propulsion (HEP) for Regional Aircraft are the Stuttgart University and EASN Academy partnership. The additional Strategy actions to grow the EV-Mobility R\&D results was supported from the AVERE EC Association [7].

1) GOAL: $100 \%$ new zero-emissions vehicles by 2030 ;

2) Fully decarbonized European road transport by 2050;

3) Making Europe a world leader in electromobility.

Close to 2.5 million electric vehicles currently on European roads. EV absolute sales more than doubled last year (2020); while sales shares tripled. The EU's Green Deal and the Recovery Plan offer unique opportunities to further scale up electromobility in coming years. We must support and accelerate the transition to zero emission mobility. Decarbonization potential Electric vehicles have 3 times lower GHG footprint than Internal Combustion Engine vehicles under the current energy mix. Clean air Electric vehicles do not produce any tailpipe pollutants such as $\mathrm{NO}_{x}$ and fine particles (PM10 and PM2.5). A rapid decline in price and growing availability More models are coming to the market in larger quantities while price per unit keeps reducing steadily. Potential for zero emissions long term as renewable energy scales up Reaching the $\mathrm{COP}_{21}$ goal of limiting temperature to $1.5^{\circ} \mathrm{C}$ will require a complete decarbonization of the transport sector by 2050. Reducing noise pollution. An electric vehicle is silent at city speeds and during acceleration. Adapting Europe's mobility sector to future global change now Electromobility is a global growth market; and Europe cannot afford to lag behind. The focus to establishing a harmonised; high quality; dense ev charging infrastructure network. The charging environment across Europe must be more consumer-friendly; seamless; interoperable; and suitable to heavy-duty vehicles. The upcoming revision of the Alternative Fuels Directive (AFID) will be crucial to support the growing amoun of EVs on European roads. It should include: The upcoming revision of the Renewable Energy Directive will be a significant opportunity:

a) Increase the target for renewable energy in transport; going beyond the $24 \%$ goal set in the Climate Target Plan for 2030

b) It should include a possibility for fuel suppliers to demonstrate compliance with their obligations via electricity crediting mechanisms.

Conclusion

Supporting AVERE priority points to new Ecology Green Tech nest aspects to realize future our patenting innovation PLUG MOBILITY RID Systems to. Harmonised rules for charging new progress hardware and operations (in the form of a regulation rather than a directive) as-a clear focus on zero-emissions mobility: setting clear targets for expansion of charging infrastructure; - improvements to quality of infrastructure and users' experience; - also establish a 'right to plug' in Buildings in the upcoming revision of the European Buildings Directive (EPBD); ensuring that consumer share never denied the right to have a charging point. To fully reap the benefits of EV-electromobility; legislation should support the rapid uptake of renewable energy; as well as of smart charging and vehicle to grid technology. also swiftly enhance Energy System Integration; specifically through the development of smart charging and vehicle to grid technology. EU power markets should permit EVs; as a decentralized energy resource; to provide flexibility services. Electro Energy Efficiency for E-Drivers Logo:

"It's Non-Stop as You Need Faster for EV-Drive Any Time and Any Where!"

\section{References}

1. Ponyev LP (2021) The New know-how PM Point LIDAR Project// Skolkovo Conference Creative Business Cup Russia.

2. (2021) Statistics of /EV-Mobility Development.

3. Ponyev LP; Ponyaeva LL (2018) The Innovation Know-How RID Project// Suvorov Awards Competition Prize by the Switzerland Embassy in Russia.

4. Ponyev LP; Ponyaeva LL (2021) The EV-Plug Mobility as New Concept POLIDAR Germany DENA Energy Efficiency Award.

5. Ponyaev LP (2011) Review of projects: - simulators for SSJ 100 aircraft//Vesti GSS magazine.

6. Ponyev LP (2016) New know-how innovation ideas for EV-Mobility Recharge Infrastructure Energy Efficiency Projection

7. Vangeel Ph (2020) AVERE Strategy Vision 2030// Press-release AVARE European EV-Mobility Association. 